\title{
Corrigendum: Toward an Energy Efficient Wastewater Treatment: Combining a Microbial Fuel Cell/Electrolysis Cell Anode With an Anaerobic Membrane Bioreactor
}

\author{
Nazli Pelin Kocatürk-Schumacher ${ }^{1,2}$, Joana Madjarov ${ }^{2}$, Pavaris Viwatthanasittiphong ${ }^{1}$ and \\ Sven Kerzenmacher ${ }^{1,2 *}$ \\ ${ }^{1}$ Center for Environmental Research and Sustainable Technology (UFT), University of Bremen, Bremen, Germany, \\ ${ }^{2}$ Laboratory for MEMS Applications, IMTEK - Department of Microsystems Engineering, University of Freiburg, Freiburg, \\ Germany
}

Keywords: bioelectrochemical systems, AnMBR, filtering anode, microbial anode, fouling mitigation, electrochemical cleaning, turbulence promotor

\section{A Corrigendum on}

OPEN ACCESS

Approved by:

Frontiers in Energy Research,

Frontiers Media SA, Switzerland

*Correspondence:

Sven Kerzenmacher kerzenmacher@uni-bremen.de

Specialty section:

This article was submitted to Fuel Cells,

a section of the journal Frontiers in Energy Research

Received: 13 February 2019 Accepted: 15 February 2019 Published: 18 March 2019

Citation: Kocatürk-Schumacher NP, Madjarov J, Viwatthanasittiphong $P$ and Kerzenmacher S (2019) Corrigendum: Toward an Energy Efficient Wastewater Treatment: Combining a Microbial Fuel Cell/Electrolysis Cell Anode With an Anaerobic Membrane Bioreactor.

Front. Energy Res. 7:25.

doi: 10.3389/fenrg.2019.00025
Toward an Energy Efficient Wastewater Treatment: Combining a Microbial Fuel Cell/Electrolysis Cell Anode With an Anaerobic Membrane Bioreactor

by Kocatürk-Schumacher, N. P., Madjarov, J., Viwatthanasittiphong, P., and Kerzenmacher, S. (2018). Front. Energy Res. 6:95. doi: 10.3389/fenrg.2018.00095

In the original article, unfortunately, the anode potential of the chronoamperometry experiments has not been reported. A correction has been made to the Materials and Methods, Experimental Setup, paragraph two:

"A Gamry PCI4/300 potentiostat (Gamry Instruments, Warminster, USA) was used for analyzing electrochemical activities of the anode in a 3 electrode setup with a saturated calomel electrode (SCE) as reference electrode (KE11, Sensortechnik Meinsberg, Germany) in all experiments. All chronoamperometry experiments were carried out at an anode potential of $-0.241 \mathrm{~V}$ vs. SCE, except during the cleaning step in the electrochemical cleaning experiments. The potentials given in $\mathrm{V}$ vs. SHE were calculated by adding $0.241 \mathrm{~V}$ to the potential measured vs. the SCE reference electrode. Counter electrodes were made from a platinum mesh (No. 900338, Chempur GmbH, Germany). All electrode positions are depicted in Figure 2. The default three-electrode positions are chosen as to minimize losses caused by uncompensated resistance (iR-drop)."

The authors apologize for this inconvenience and state that this does not change the scientific conclusions of the article in any way. The original article has been updated.

Copyright $\odot 2019$ Kocatürk-Schumacher, Madjarov, Viwatthanasittiphong and Kerzenmacher. This is an open-access article distributed under the terms of the Creative Commons Attribution License (CC BY). The use, distribution or reproduction in other forums is permitted, provided the original author(s) and the copyright owner $(s)$ are credited and that the original publication in this journal is cited, in accordance with accepted academic practice. No use, distribution or reproduction is permitted which does not comply with these terms. 